\title{
Diabetic Pathophysiology Enhances Inflammation during Extracorporeal Membrane Oxygenation in a Rat Model
}

\author{
Yutaka Fujii $^{1, *}$, Takuya Abe ${ }^{1}$ and Kikuo Ikegami ${ }^{2}$ \\ 1 Department of Clinical Engineering and Medical Technology, Niigata University of Health and Welfare, \\ Niigata 950-3198, Japan; takuya-abe@nuhw.ac.jp \\ 2 Department of Health and Medical Sciences, Chiba Institute of Science, Choshi 288-0025, Japan; \\ kikegami@cis.ac.jp \\ * Correspondence: fujii@nuhw.ac.jp
}

Citation: Fujii, Y.; Abe, T.; Ikegami, K. Diabetic Pathophysiology Enhances Inflammation during Extracorporeal Membrane Oxygenation in a Rat Model. Membranes 2021, 11, 283. https://doi.org/10.3390/ membranes11040283

Academic Editor: Fabio Silvio Taccone

Received: 29 March 2021

Accepted: 9 April 2021

Published: 11 April 2021

Publisher's Note: MDPI stays neutral with regard to jurisdictional claims in published maps and institutional affiliations.

Copyright: (c) 2021 by the authors. Licensee MDPI, Basel, Switzerland. This article is an open access article distributed under the terms and conditions of the Creative Commons Attribution (CC BY) license (https:/ / creativecommons.org/licenses/by/ $4.0 /)$.

\begin{abstract}
Systemic inflammatory responses in patients undergoing extracorporeal membrane oxygenation (ECMO) contribute significantly to ECMO-associated morbidity and mortality. In recent years, the number of type 2 diabetes mellitus patients has increased, and the number of these patients undergoing ECMO has also increased. Type 2 diabetes mellitus is a high-risk factor for complications during ECMO. We studied the effects of ECMO on inflammatory response in a diabetic rat ECMO model. Twenty-eight rats were divided into 4 groups: normal SHAM group (normal rats: $n=7$ ), diabetic SHAM group (diabetic rats: $n=7$ ), normal ECMO group (normal rats: $n=7$ ), and diabetic ECMO group (diabetic rats: $n=7$ ). We measured the plasma levels of cytokines, tumor necrosis factor- $\alpha$, and interleukin-6. Aspartate aminotransferase (AST), alanine aminotransferase (ALT), lactate dehydrogenase (LDH), blood urea nitrogen (BUN), creatinine $(\mathrm{Cr})$, and liver-type fatty acid binding protein (L-FABP) were examined in the rat cardiopulmonary bypass model to ascertain organ damage. In addition, the lung wet-to-dry weight (W/D) ratio was measured as an index of pulmonary tissue edema. A pathologic evaluation of kidneys was conducted by hematoxylin-eosin (HE) and periodic-acid-methenamine-silver (PAM) staining. In the diabetic ECMO group, levels of cytokines, AST, ALT, LDH, and L-FABP increased significantly, reaching a maximum at the end of ECMO in comparison with other groups $(p<0.05)$. In addition, hematoxylin-eosin and periodic acid-methenamine-silver staining of renal tissues showed marked injury in the ECMO group (normal ECMO and diabetic ECMO groups). Furthermore, when the normal ECMO and diabetic ECMO groups were compared, severe organ injury was seen in the diabetic ECMO group. There was remarkable organ injury in the diabetic ECMO group. These data demonstrate that diabetes enhances proinflammatory cytokine release, renal damage, and pulmonary edema during ECMO in an animal model.
\end{abstract}

Keywords: ECMO; diabetes; inflammatory response; rat ECMO model

\section{Introduction}

Extracorporeal membrane oxygenation (ECMO) is known to cause a variety of complications while saving patients [1-3]. ECMO has multiple adverse effects with a systemic inflammatory response, mainly caused by blood coming in contact with the artificial foreign surface of the ECMO circuit [1-3]. This complex inflammatory chain reaction significantly affects the morbidity and mortality associated with extracorporeal life support (ECLS) [4].

In addition to contact with the ECMO unit, other potential factors involved in the inflammatory response include endotoxemia, ischemic reperfusion injury, and vascular hyperpermeability [2,3]. In addition, an increase in cytokines during ECMO aggravates the pro-inflammatory chain reaction $[2,3,5]$. Our recent study demonstrated that ECLS causes principal organ damage and a systemic inflammatory response in a small animal ECMO model [6-8]. ECMO has been commonly used in the world to support patients with severe 
pneumonia [9-12]. The active use of ECMO was also recommended for severe pneumonia from COVID-19, which has been rampant since 2020 [13].

Recently, the number of type 2 diabetes mellitus patients has been increasing, and the number of cardiac surgical procedures for these patients is also increasing [14]. Patients with diabetes experience increased activation of macrophages, which causes chronic inflammation $[15,16]$. ECLS in patients with diabetes may cause further inflammation. In the present study, ECMO's effect was examined in a type 2 diabetic rat model.

In addition, the lung wet-to-dry weight (W/D) ratio was measured as an index of pulmonary tissue edema. A pathologic evaluation of kidneys by hematoxylin-eosin (HE) and periodic-acid-methenamine-silver (PAM) staining was also performed.

\section{Materials and Methods}

\subsection{Animals}

This study was performed in accordance with the National Institutes of Health's guidelines for laboratory animal welfare. Sprague-Dawley rats (males, 14-16 w, 400-450 g, $n=14$ ) and Spontaneously Diabetic Torii rats (males, 14-16 w, 400-450 g, $n=14$ ) were housed 3 per cage under a $12 \mathrm{~h}$ light-dark cycle with food and water available ad libitum. All animals were provided by CLEA Japan, Inc. (Tokyo, Japan).

\subsection{Anesthesia, Surgical Preparation, and ECMO}

After the rats were anesthetized by $4.5-5.0 \%$ isoflurane-mixed oxygen-enriched air inhalation with a vaporizer, they were placed in the supine position, and a rectal temperature probe was then inserted. The rats were orotracheally intubated using a $14 \mathrm{G}$ cannula (Terumo Corp., Tokyo, Japan) and ventilated with a respirator for small animals (Model 683, Harvard Apparatus Ltd., Holliston, MA, USA). Ventilation was volume-controlled at a frequency of 70 breaths $/ \mathrm{min}$, a tidal volume of $10 \mathrm{~mL} / \mathrm{kg}$, and an inspired oxygen fraction of $40 \%$. Anesthesia was maintained with 1.5-2.0\% isoflurane (without neuromuscular blocking agents), and the rectal temperature was maintained at $35.5-36.5{ }^{\circ} \mathrm{C}$ throughout the experiment. The right femoral artery was cannulated with polyethylene tubing (inner diameter $0.5 \mathrm{~mm}$, outer diameter $0.8 \mathrm{~mm}$ : Natsume Seisakusho Co. Ltd., Tokyo, Japan) for monitoring the arterial blood pressure using a Power-Lab (ML880, AD Instruments, Bella Vista, NSW, Australia). A polyethylene tubing (inner diameter $0.8 \mathrm{~mm}$, outer diameter $1.2 \mathrm{~mm}$ : Natsume Seisakusho Co. Ltd., Tokyo, Japan) was used to cannulate the left common carotid artery as the outflow cannula for the ECMO system, as described in our previous reports [6-8]. Heparin sodium (500 IU/kg) was then administered through the outflow cannula. The right internal jugular vein was cannulated with A $16 \mathrm{G}$ cannula with 4-side holes (depth 38 mm: Togomedkit Co., Ltd., Tokyo, Japan) for venous uptake. The same person conducted all experiments to standardize the procedure. The ECMO system was composed of a polyvinyl chloride tubing circuit (Senko Medical Co., Ltd., Tokyo, Japan), a specially designed membranous oxygenator for small animals (polypropylene, membrane area $0.03 \mathrm{~m}^{2}$ : Senko Medical Co., Ltd., Osaka, Japan), and a mini roller pump (REGLO Digital ISM831, ISMATEC, Wertheim, Germany) primed by $7 \mathrm{~mL}$ of saline and 1 $\mathrm{mL}(1000 \mathrm{IU})$ of heparin. Figure 1 shows the experimental conditions. 


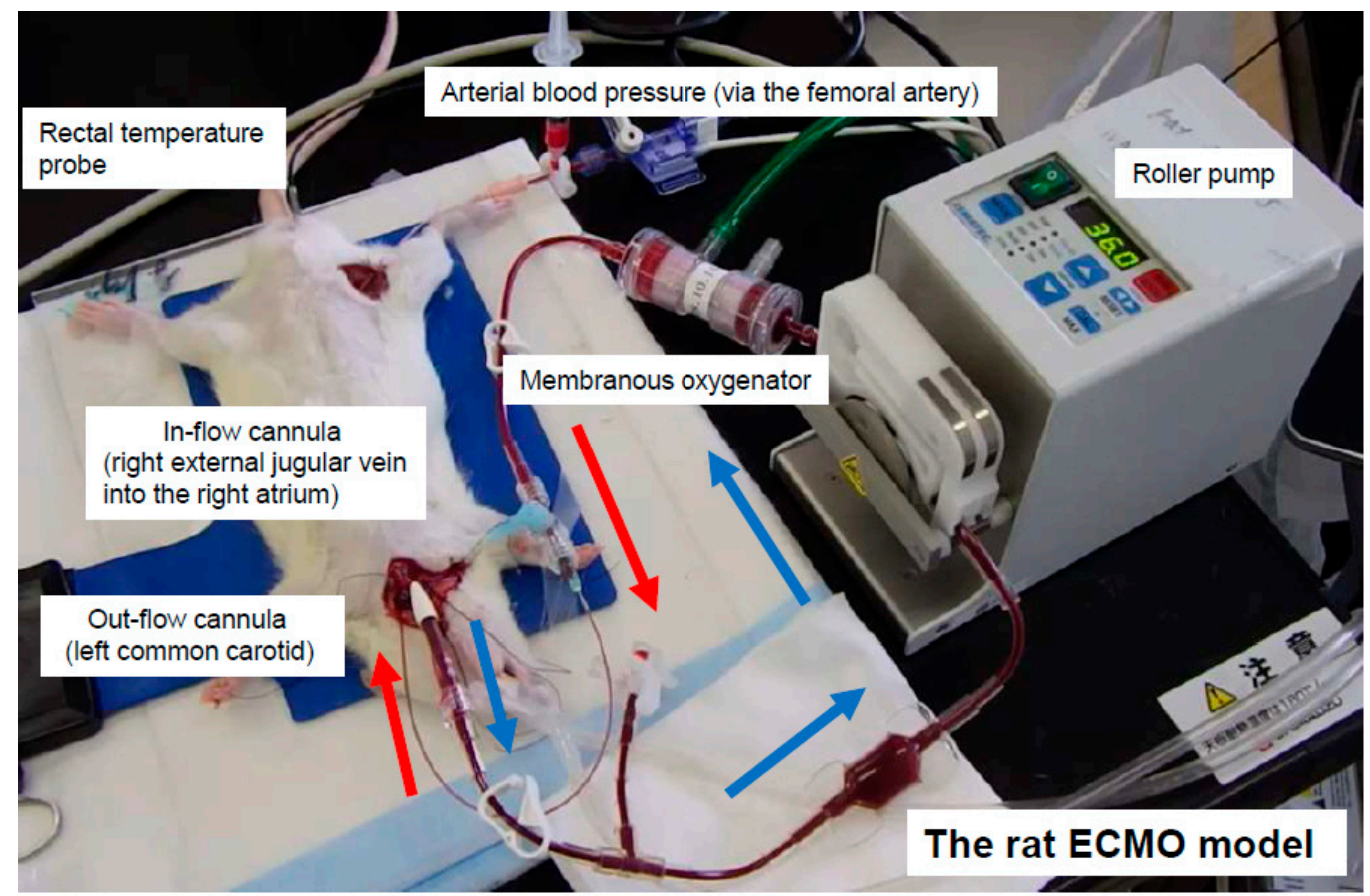

Figure 1. Extracorporeal circulation in a rat extracorporeal membrane oxygenation (ECMO) model.

\subsection{Experimental Design}

Twenty-eight rats were divided into 4 groups: normal SHAM group (normal rats: $n=7$ ), diabetic SHAM group (diabetic rats: $n=7$ ), normal ECMO group (normal rats: $n=7$ ), and diabetic ECMO group (diabetic rats: $n=7$ ). The normal SHAM and diabetic SHAM group only underwent surgical preparation without ECMO. The ECMO perfusion flow was initiated and maintained at $60-70 \mathrm{~mL} / \mathrm{kg} / \mathrm{min}$. The arterial pressures of carbon dioxide $\left(\mathrm{PaCO}_{2}\right)$ and oxygen $\left(\mathrm{PaO}_{2}\right)$ were maintained at $35-45 \mathrm{mmHg}$ and $250-350 \mathrm{mmHg}$, respectively, and managed with $\alpha$-stat. Blood samples were collected at 5 defined time points, before ECMO (pre-ECMO) and $30 \mathrm{~min}, 60 \mathrm{~min}, 90 \mathrm{~min}$, and $120 \mathrm{~min}$ after the initiation of ECMO (end-ECMO). Figure 2 shows the schematic diagram of the experimental design. Saline was used for fluid replacement management. Saline was injected in $1.0 \mathrm{~mL}$ increments at blood sampling (total injection volume: $5.0 \mathrm{~mL}$ during the experiment).

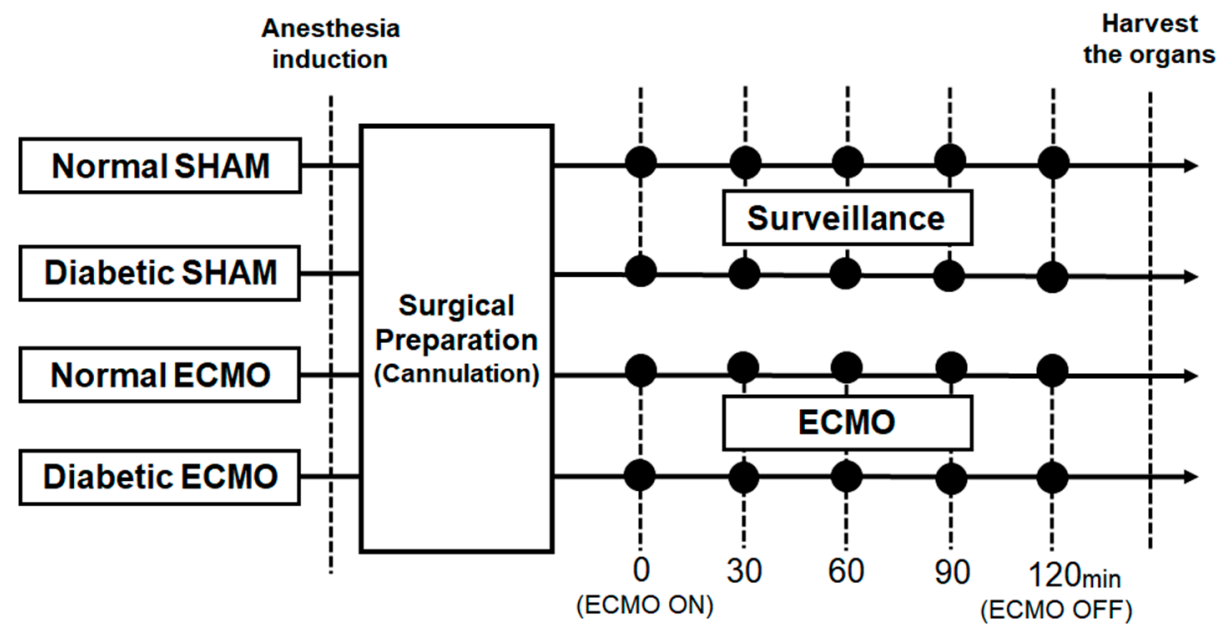

Blood-sampling points

Figure 2. Schematic diagram of experimental design. 
To evaluate the systemic inflammatory responses, tumor necrosis factor- $\alpha$ (TNF- $\alpha)$ and interleukin (IL)-6 were measured by an enzyme-linked immunosorbent assay (BioPlex Assay Kits, BIO-RAD Laboratories, Inc., Hercules, CA, USA). The concentrations of aspartate aminotransferase (AST), alanine aminotransferase (ALT), lactate dehydrogenase $(\mathrm{LDH})$, blood urea nitrogen $(\mathrm{BUN})$, and creatinine $(\mathrm{Cr})$ were used to evaluate organ damage and were measured by automated colorimetry from blood plasma samples (DRI-CHEM 7000 Analyzer, FUJIFILM, Kanagawa, Japan). Liver-type fatty acid binding protein (LFABP) was used as a biochemical marker for acute renal dysfunction [17] measured by a rat L-FABP ELISA kit (CMIC Co., Ltd., Tokyo, Japan).

Blood gases, $\mathrm{pH}$, hemoglobin $(\mathrm{Hb})$ concentration, and electrolytes were also measured (VetStat Electrolyte and Blood Gas Analyzer, IDEXX, Sydney, NSW, Australia). All animals were euthanized at the end of the experiment using a potassium chloride injection into the heart. The left lung was harvested and divided into 3 parts. The left lung superior-third was used for the calculation of the $W / D$ ratio. The lung block was weighed before and after desiccation for $48 \mathrm{~h}$ in a dry oven at $70{ }^{\circ} \mathrm{C}[6,7]$.

In addition, 3- $\mu \mathrm{m}$ thick, formalin-fixed, paraffin-embedded sections were stained with HE and PAM to assess renal pathology at the end of the experiment.

\subsection{Statistics}

All data are expressed as means \pm standard error (SE). The comparisons among groups were performed by analysis of variance. The Fisher protected least significant difference (PLSD) post hoc test was used for subsequent comparisons between groups at the same time points. All statistical analyses were performed using Stat View 5.0 (Abacus Concepts, Berkeley, CA, USA). Additionally, $p<0.05$ was considered statistically significant.

\section{Results}

Table 1 shows the changes in hemodynamic variables, $\mathrm{Hb}$ concentration, $\mathrm{PaO}_{2}$, and $\mathrm{PaCO}_{2}$ in each group. Mean arterial pressure (MAP) and $\mathrm{Hb}$ were significantly decreased during ECMO in both normal and diabetic ECMO groups.

Table 1. Hemodynamic variables, blood gas partial pressures, hemoglobin, and $\mathrm{pH}$ before and during ECMO.

\begin{tabular}{|c|c|c|c|c|}
\hline Variable & Group & Pre-ECMO & ECMO $60 \mathrm{~min}$ & ECMO $120 \mathrm{~min}$ \\
\hline \multirow[t]{4}{*}{ MAP (mmHg) } & Normal SHAM & $99 \pm 3$ & $92 \pm 6$ & $84 \pm 5$ \\
\hline & Diabetic SHAM & $94 \pm 3$ & $88 \pm 4$ & $83 \pm 5$ \\
\hline & Normal ECMO & $97 \pm 3$ & $76 \pm 5^{+*}$ & $75 \pm 4^{+*}$ \\
\hline & Diabetic ECMO & $96 \pm 2$ & $79 \pm 4^{+*}$ & $77 \pm 4^{t *}$ \\
\hline \multirow[t]{4}{*}{ HR (beat/min) } & Normal SHAM & $368 \pm 12$ & $366 \pm 11$ & $374 \pm 5$ \\
\hline & Diabetic SHAM & $353 \pm 10$ & $349 \pm 11$ & $360 \pm 9$ \\
\hline & Normal ECMO & $375 \pm 11$ & $369 \pm 14$ & $343 \pm 7^{+*}$ \\
\hline & Diabetic ECMO & $362 \pm 11$ & $357 \pm 18$ & $346 \pm 14^{+*}$ \\
\hline \multirow[t]{4}{*}{$\mathrm{PaO}_{2}(\mathrm{mmHg})$} & Normal SHAM & $98 \pm 2$ & $98 \pm 2$ & $102 \pm 4$ \\
\hline & Diabetic SHAM & $100 \pm 2$ & $99 \pm 2$ & $98 \pm 1$ \\
\hline & Normal ECMO & $100 \pm 4$ & $301 \pm 21^{+*}$ & $290 \pm 19^{+*}$ \\
\hline & Diabetic ECMO & $102 \pm 4$ & $289 \pm 20^{\dagger *}$ & $295 \pm 17^{\dagger *}$ \\
\hline \multirow[t]{4}{*}{$\mathrm{PaCO}_{2}(\mathrm{mmHg})$} & Normal SHAM & $40 \pm 2$ & $40 \pm 1$ & $38 \pm 3$ \\
\hline & Diabetic SHAM & $39 \pm 1$ & $38 \pm 2$ & $39 \pm 1$ \\
\hline & Normal ECMO & $40 \pm 1$ & $39 \pm 1$ & $38 \pm 1$ \\
\hline & Diabetic ECMO & $41 \pm 1$ & $39 \pm 1$ & $38 \pm 1$ \\
\hline \multirow[t]{4}{*}{$\mathrm{Hb}(\mathrm{g} / \mathrm{dL})$} & Normal SHAM & $14.1 \pm 0.5$ & $13.9 \pm 0.5$ & $13.0 \pm 0.6$ \\
\hline & Diabetic SHAM & $14.0 \pm 0.4$ & $12.6 \pm 0.5$ & $12.9 \pm 0.5$ \\
\hline & Normal ECMO & $14.4 \pm 0.2$ & $10.4 \pm 0.5^{\dagger *}$ & $10.2 \pm 0.5^{\dagger *}$ \\
\hline & Diabetic ECMO & $14.0 \pm 0.2$ & $10.3 \pm 0.7^{\dagger *}$ & $10.5 \pm 0.5^{\dagger *}$ \\
\hline
\end{tabular}


Table 1. Cont.

\begin{tabular}{ccccc}
\hline Variable & Group & Pre-ECMO & ECMO 60 min & ECMO 120 min \\
\hline \multirow{2}{*}{$\mathrm{pH}$} & Normal SHAM & $7.35 \pm 0.03$ & $7.37 \pm 0.03$ & $7.40 \pm 0.03$ \\
& Diabetic SHAM & $7.36 \pm 0.02$ & $7.37 \pm 0.03$ & $7.39 \pm 0.02$ \\
& Normal ECMO & $7.37 \pm 0.02$ & $7.38 \pm 0.02$ & $7.39 \pm 0.03$ \\
& Diabetic ECMO & $7.37 \pm 0.02$ & $7.40 \pm 0.01$ & $7.40 \pm 0.02$ \\
\hline
\end{tabular}

Variables are expressed by mean \pm standard error. ${ }^{\dagger} p<0.05$ versus Normal SHAM group at the same time, ${ }^{*} p<0.05$ versus Diabetic SHAM group at the same time. MAP: mean arterial pressure, HR: heart rate, $\mathrm{PaO}_{2}$ partial pressure of arterial oxygen, $\mathrm{PaCO}_{2}$ : partial pressure of arterial carbon dioxide, $\mathrm{Hb}$ : hemoglobin, and $\mathrm{pH}$ : power of hydrogen.

The $\mathrm{PaO}_{2}$ levels were significantly higher $(p<0.05)$ in the ECMO group (normal ECMO and diabetic ECMO groups) than in the SHAM group (normal SHAM and diabetic SHAM groups), although the differences were not statistically significant. In contrast, no statistical difference was found in the $\mathrm{PaCO}_{2}$ level between these groups.

Before ECMO, plasma levels of cytokines were not significantly different among the normal SHAM group, diabetic SHAM group, normal ECMO group, or diabetic ECMO group. However, $\mathrm{Cr}, \mathrm{BUN}$, and L-FABP were significantly higher in the diabetic groups (diabetic SHAM and diabetic ECMO groups) than in the normal groups (diabetic SHAM and diabetic ECMO groups) before ECMO. Plasma levels of cytokines, AST, ALT, LDH, $\mathrm{Cr}$, BUN, and L-FABP remained unchanged during the experimental period in the SHAM groups (normal SHAM and diabetic SHAM groups). In the diabetic ECMO group, proinflammatory cytokines increased significantly, reaching a maximum at the end of ECMO $(\mathrm{TNF}-\alpha, 1576 \pm 255 \mathrm{pg} / \mathrm{mL} ; \mathrm{IL}-6,2620 \pm 599 \mathrm{pg} / \mathrm{mL})$.

In the diabetic ECMO group, levels of AST, ALT, LDH, and L-FABP increased significantly, reaching a maximum at the end of ECMO in comparison with other groups (LDH, $845 \pm 158 \mathrm{U} / \mathrm{L} ; \mathrm{AST}, 220 \pm 17 \mathrm{U} / \mathrm{L}$; ALT, $116 \pm 12 \mathrm{U} / \mathrm{L} ; \mathrm{L}-\mathrm{FABP}, 698 \pm 80 \mathrm{U} / \mathrm{mL}$ ). In terms of $\mathrm{Cr}$ and BUN, the diabetic groups (diabetic SHAM group and diabetic ECMO group) showed significantly higher levels $(p<0.05)$ during the experimental period (Figure 3 ).
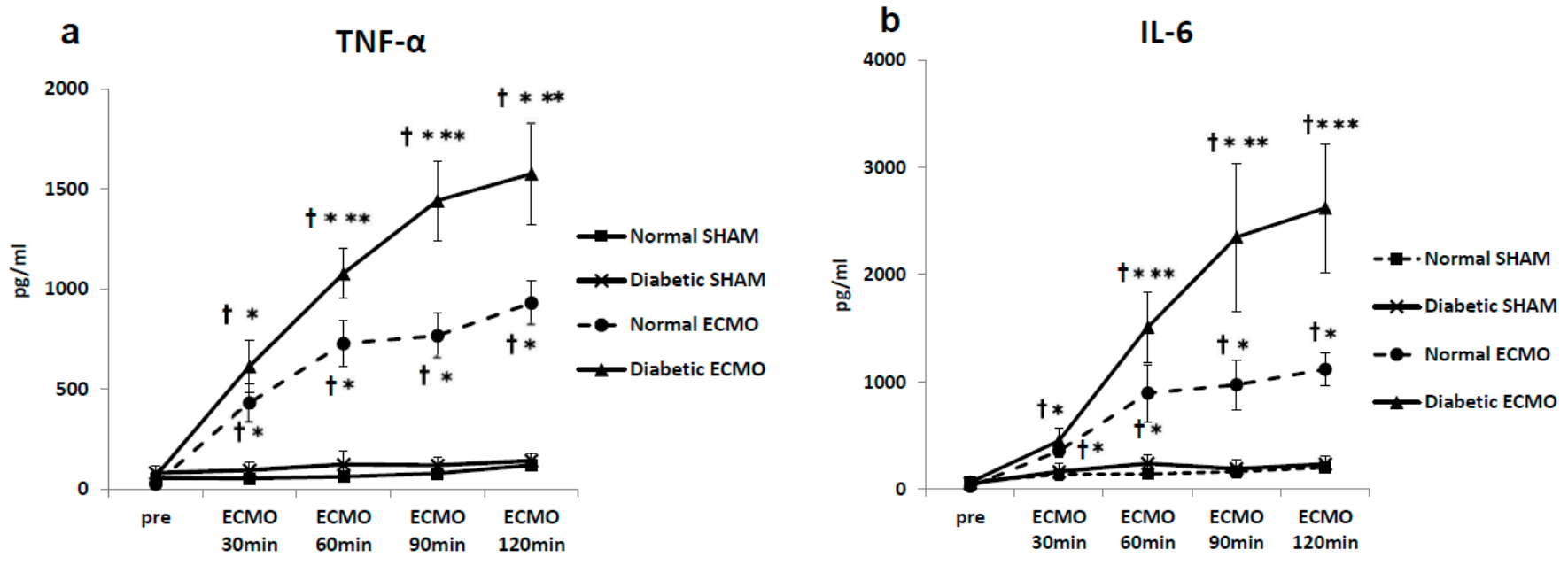

Figure 3. Cont. 

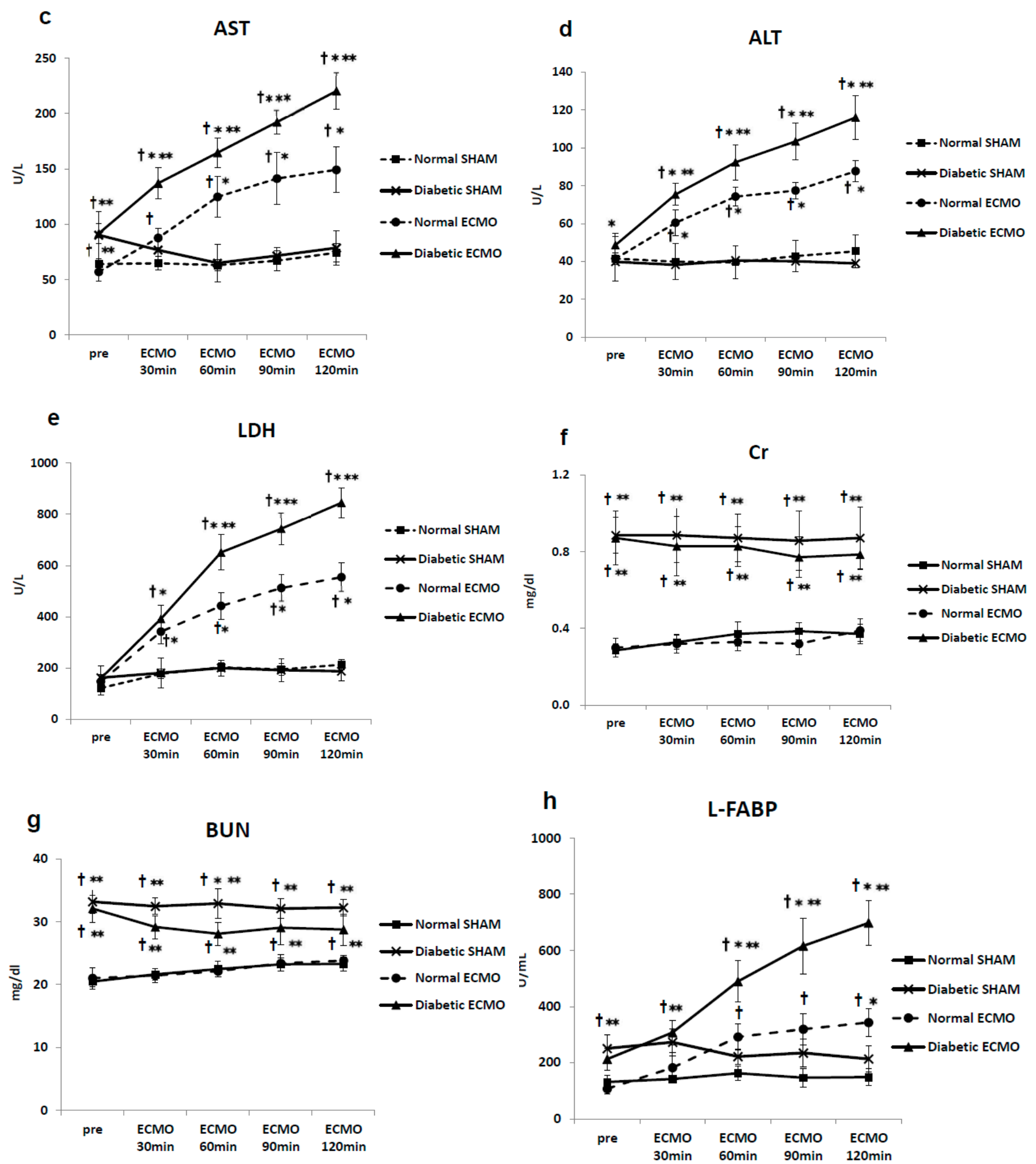

Figure 3. Plasma tumor necrosis factor (TNF)- $\alpha$ (a), interleukin (IL)-6 (b), aspartate aminotransferase (AST) (c), aminotransferase (ALT) (d), lactate dehydrogenase (LDH) (e), creatinine (Cr) (f), blood urea nitrogen (BUN) (g), and liver-type fatty acid binding protein (L-FABP) (h). ${ }^{\dagger} p<0.05$ versus normal SHAM group at the same time point, ${ }^{*} p<0.05$ versus diabetic SHAM group at the same time point, ${ }^{* *} p<0.05$ versus normal cardiopulmonary bypass group at the same time point.

The $\mathrm{W} / \mathrm{D}$ ratio was much higher in the ECMO groups (normal ECMO and diabetic ECMO groups) than in the SHAM groups (normal SHAM and diabetic SHAM groups) Additionally, the diabetic ECMO group showed a significantly higher $\mathrm{W} / \mathrm{D}$ ratio than 
the normal ECMO group (normal ECMO group, $5.74 \pm 0.16$ vs. diabetic ECMO group, $6.20 \pm 0.20(p<0.05)$ (Figure 4).

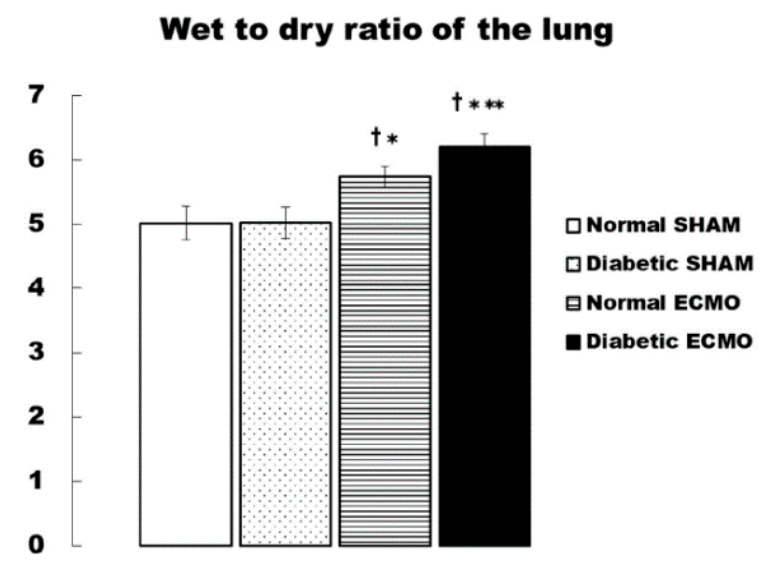

Figure 4. Wet-to-dry (W/D) ratio of the left lung at the end of cardiopulmonary bypass. ${ }^{\dagger} p<0.05$ versus normal SHAM group at the same time, ${ }^{*} p<0.05$ versus diabetic SHAM group at the same time, ${ }^{* *} p<0.05$ versus normal ECMO group at the same.

The extent of renal tubular damage assessed by histologic analyses is shown in Figure 5. The HE and PAM staining of renal tissues showed marked injury in the ECMO group (normal ECMO and diabetic ECMO groups). Furthermore, when the normal ECMO and diabetic ECMO groups were compared, the injury was severe in the diabetic ECMO group. Specifically, glomerular atrophy and severe tubular injury were observed in the diabetic ECMO group.

\section{Morphological analysis Normal vs. Diabetes}

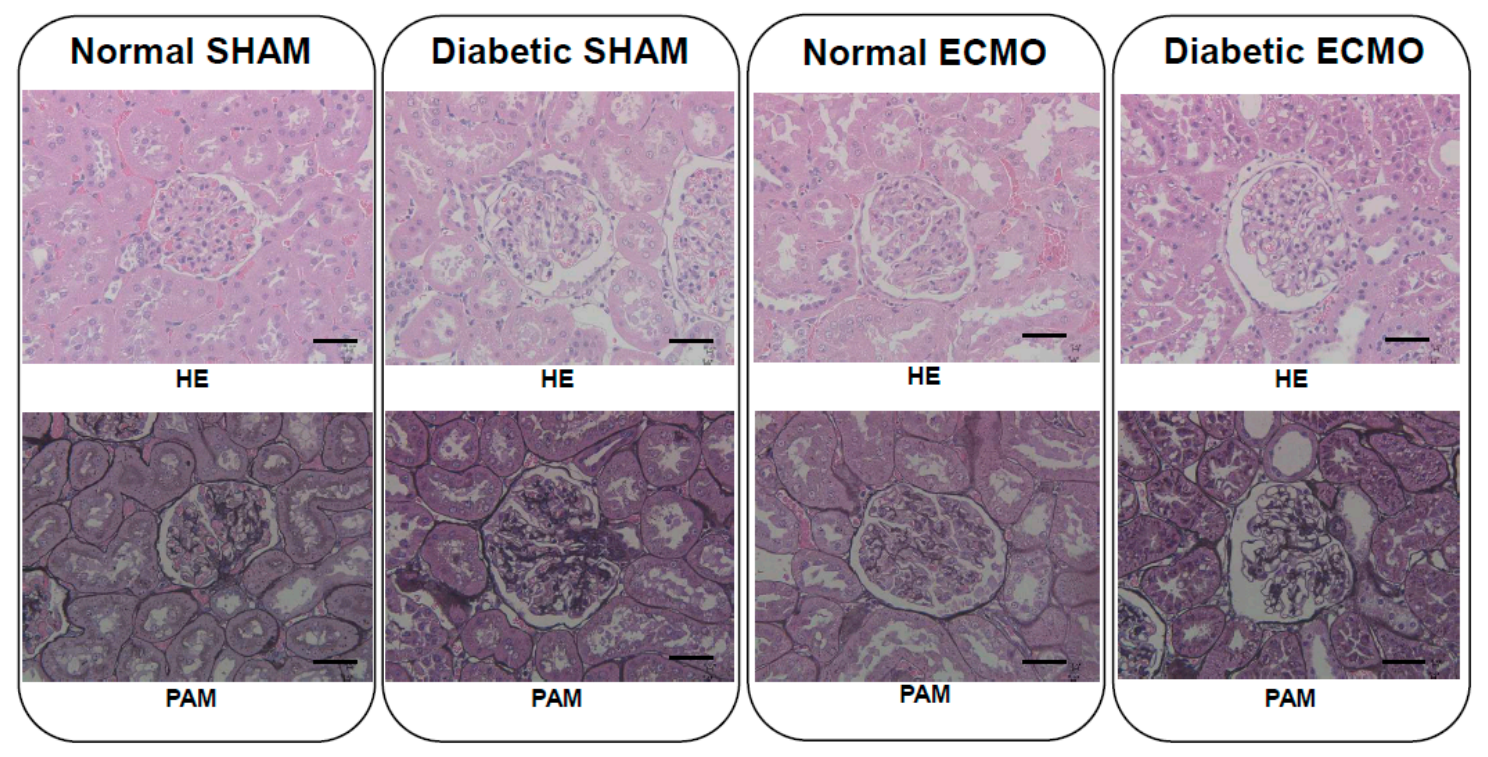

Figure 5. Pathological image of renal tissue (at 200-fold magnification). HE, hematoxylin-eosin; PAM, periodic acidmethenamine-silver stain. Scale bar: $50 \mu \mathrm{m}$. Normal SHAM: Intact. Diabetic SHAM: Slight cytolysis was shown, and the organ structure was maintained. Normal ECMO: Cell injury was similar to the level of diabetic SHAM rats. Diabetic ECMO: Tubular epithelium was desquamated from the basement membrane. 


\section{Discussion}

It is well known that ECLS causes a pro-inflammatory chain reaction via blood interactions with the artificial extracorporeal device $[18,19]$. The present study using an experimental rat model also demonstrated that ECMO treatment increased plasma levels of the inflammatory markers, TNF- $\alpha$ and IL-6, in the normal SHAM group, as shown in Figure 3 . The systemic inflammatory response may be critically important for the perioperative outcome $[20,21]$. Furthermore, in recent years, cardiovascular surgery for patients with diabetes has been increasing [22]. The diabetic population accounts for more than $38 \%$ of patients undergoing cardiac operations, especially coronary revascularization, in the world [22].

In the present study, we examined the effect of a type 2 diabetic setting during ECMO treatment on the inflammatory response in an animal model. The major finding of this study was that rats with diabetes in the ECMO model showed rapidly increased inflammatory cytokines, such as TNF- $\alpha$ and IL-6, and other measurements, such as AST, ALT, LDH and L-FABP. There were no differences in inflammatory cytokines and all biochemical data between the diabetic SHAM and diabetic ECMO groups before the experiment. The rapidly increased inflammatory cytokines and all biochemical data imply that these findings are due to ECMO. The pulmonary tissues of the rats in the diabetic ECMO group had higher $\mathrm{W} / \mathrm{D}$ ratios at the end of ECMO than the other groups, and, therefore, they were presumed to have accumulated more water. Furthermore, in the diabetic ECMO group, it is presumed that renal damage was caused by a sharp rise in the acute renal failure markers, L-FABP, severe tubular damage, and glomerular atrophy.

People with diabetes and other lifestyle-related diseases are prone to arteriosclerosis, and mast cells in these patients are thought to cause cell death and chronic inflammation [23]. ECMO further enhances the inflammatory response and likely induces a rapid release of cytokines. Furthermore, it is well known that vascular endothelial dysfunction resulting in ischemia occurs in vulnerable organs in the diabetic setting [24,25]. In particular, the kidney is susceptible to damage by ECLS $[26,27]$. In this study, non-physiologic circulation by ECMO was considered closely associated with acute kidney injury (AKI). It has also been reported that mesenteric endothelial dysfunction occurs in animal experiments using a diabetes model [28]. Furthermore, a previous study showed the effects of green tea polyphenols on acute kidney injury after cardiopulmonary bypass in diabetes rats [29].

In addition, it was observed that the tendency for pulmonary edema was severe in the diabetes groups, and vascular permeability was enhanced. Previously, the relationship between diabetic pathogenesis and oxidative stress has attracted attention [30,31]. There are some reports that patients with diabetes are susceptible to oxidative stress leading to inflammation and organ damage during cardiac surgery $[32,33]$. Typically, however, arterial pressure of oxygen is maintained at high levels in clinical ECLS [34]. Our previous study also showed that oxidative stress generates superoxide was redundant to the systemic inflammatory response in ECLS [7]. Several studies have shown that the ECMO circuit's inner side of the walls activates leukocytes, platelets, and the complement system. Activated leukocytes release cytotoxic agents and reactive oxygen species associated with the systemic inflammatory response and organ damage $[35,36]$. Our previous study showed that selective reduction of hydroxyl radicals with hydrogen gas attenuates both pro-inflammatory cytokines-TNF- $\alpha$ and IL-6 - suggesting that this radical acts to non-selectively increase these cytokines [6]. The present animal study demonstrated that a diabetic setting causes the elevation of cytokines and organ damage in the lungs and kidneys in comparison with the normal group treated with ECMO. Future studies focusing on oxidative stress in diabetic patients during ECMO should enable us to more deeply understand the sequential mechanism. In addition, aggressive leukocyte and cytokine removal therapies should be considered to suppress the inflammation during ECMO. Various leukocyte depletion filters have been developed in the field of cardiopulmonary bypass [37]. Furthermore, 
polymethyl methacrylate materials are known to remove cytokines [38]. Applying this technology to ECMO will lead to inflammation suppression.

Recently, new biomarkers for the early detection of AKI have been attracting attention $[17,39]$. In our present study, L-FABP was observed to increase in the diabetic groups immediately after ECMO induction. The research model used in the present study may help clarify the mechanism of injury in diabetic patients undergoing ECMO and suggest treatment and preventive measures for this injury in the future.

\section{Conclusions}

In conclusion, we report that ECMO treatment enhances the systemic release of proinflammatory cytokines and causes renal damage and pulmonary edema in rats with diabetes. These conditions are associated with a systemic inflammatory process and may result from un-physiologic tissue perfusion. Principal organ injury may play a key role in the development of multiple organ failure after ECMO and trigger higher postoperative mortality and perioperative complications that occur in diabetic patients undergoing ECMO.

Limitations: There are several limitations to the present study. First, we evaluated parameters during short-term ECMO. Further studies are needed to assess the systemic inflammatory response and organ damage during long-term ECMO and after weaning ECMO. Second, this study was not able to observe differences due to the severity of diabetes. Symptoms of diabetes are variable and vary from patient to patient. Future studies will allow us to elucidate the sequential mechanisms of the pathologic condition by evaluating the histopathological severity of diabetes.

Author Contributions: Y.F., T.A. and K.I. conceived and designed the study. Y.F. performed the experiment and analyzed the data. Y.F. wrote the manuscript. T.A. and K.I. revised the manuscript. All authors have read and agreed to the published version of the manuscript.

Funding: This research was funded by JSPS KAKENHI, grant number 25871231 and 18K08926.

Institutional Review Board Statement: The study was conducted according to the guidelines of the National Institutes of Health's for laboratory animal welfare, and approved by the Institutional Review Board of Niigata University of Health and Welfare Animal Care and Use Committee (protocol code 30009,28010 date of approval January 2018).

Conflicts of Interest: The authors declare no competing interests.

$\begin{array}{ll}\text { Abbreviations } \\ \text { ECMO } & \text { Extracorporeal membrane oxygenation } \\ \text { ECLS } & \text { Extracorporeal life support } \\ \mathrm{PaO}_{2} & \text { Arterial pressure of oxygen } \\ \mathrm{PaCO}_{2} & \text { Arterial pressure of carbon dioxide } \\ \mathrm{TNF}-\alpha & \text { Tumor necrosis factor- } \alpha \\ \mathrm{IL} & \text { Interleukin } \\ \mathrm{AST} & \text { Aspartate aminotransferase } \\ \mathrm{ALT} & \text { Alanine aminotransferase } \\ \mathrm{LDH} & \text { Lactate dehydrogenase } \\ \mathrm{BUN} & \text { Blood urea nitrogen } \\ \mathrm{Cr} & \text { Creatinine } \\ \mathrm{L}-\mathrm{FABP} & \text { Liver-type fatty acid binding protein } \\ \mathrm{Hb} & \text { Hemoglobin } \\ \mathrm{HE} & \text { Hematoxylin-eosin } \\ \mathrm{PAM} & \text { Periodic-acid-methenamine-silver stain } \\ \text { W/D } & \text { Wet-to-dry } \\ \mathrm{SE} & \text { Standard error } \\ \mathrm{ANOVA} & \text { Analysis of variance } \\ \mathrm{PLSD} & \text { Protected least significant difference }\end{array}$




\section{References}

1. Gulkarov, I.; Khusid, E.; Worku, B.; Demissie, S.; Guerges, M.; Salemi, A.; D'Ayala, M. Meta-Analysis of the Effect of Vascular Complications on Mortality in Patients Undergoing Femoral Venoarterial Extracorporeal Membrane Oxygenation. Ann. Vasc Surg. 2020, 71, 488-495. [CrossRef]

2. Roumy, A.; Liaudet, L.; Rusca, M.; Marcucci, C.; Kirsch, M. Pulmonary complications associated with veno-arterial extra-corporeal membrane oxygenation: A comprehensive review. Crit. Care 2020, 24, 1-10. [CrossRef] [PubMed]

3. Millar, J.E.; Fanning, J.P.; McDonald, C.I.; McAuley, D.F.; Fraser, J.F. The inflammatory response to extracorporeal membrane oxygenation (ECMO): A review of the pathophysiology. Crit. Care 2016, 20, 1-10. [CrossRef] [PubMed]

4. Al-Fares, A.; Pettenuzzo, T.; Del Sorbo, L. Extracorporeal life support and systemic inflammation. Intensive Care Med. Exp. 2019, 7, 1-14. [CrossRef]

5. Frerou, A.; Lesouhaitier, M.; Gregoire, M.; Uhel, F.; Gacouin, A.; Reizine, F.; Moreau, C.; Loirat, A.; Maamar, A.; Nesseler, N.; et al. Venoarterial extracorporeal membrane oxygenation induces early immune alterations. Crit. Care 2021, 25, 1-12. [CrossRef]

6. Fujii, Y.; Shirai, M.; Inamori, S.; Shimouchi, A.; Sonobe, T.; Tsuchimochi, H.; Pearson, J.T.; Takewa, Y.; Tatsumi, E.; Taenaka, Y. Insufflation of hydrogen gas restrains the inflammatory response of cardiopulmonary bypass in a rat model. Artif. Organs 2013, 37, 136-141. [CrossRef]

7. Fujii, Y.; Shirai, M.; Tsuchimochi, H.; Pearson, J.T.; Takewa, Y.; Tatsumi, E.; Taenaka, Y. Hyperoxic condition promotes an inflammatory response during cardiopulmonary bypass in a rat model. Artif. Organs 2013, 37, 1034-1040. [CrossRef]

8. Sukumaran, V.; Tsuchimochi, H.; Fujii, Y.; Hosoda, H.; Kangawa, K.; Akiyama, T.; Shirai, M.; Tatsumi, E.; Pearson, J.T. Ghrelin pre-treatment attenuates local oxidative stress and end organ damage during cardiopulmonary bypass in anesthetized rats. Front. Physiol. 2018, 9, 196. [CrossRef] [PubMed]

9. Papazian, L.; Aubron, C.; Brochard, L.; Chiche, J.-D.; Combes, A.; Dreyfuss, D.; Forel, J.M.; Guérin, C.; Jaber, S.; Mekontso-Dessap, A.; et al. Formal guidelines: Management of acute respiratory distress syndrome. Ann. Intensive Care 2019, 9, 1-18. [CrossRef]

10. Grant, A.A.; Hart, V.J.; Lineen, E.B.; Badiye, A.; Byers, P.M.; Patel, A.; Vianna, R.; Koerner, M.M.; El Banayosy, A.; Loebe, M.; et al. A weaning protocol for venovenous extracorporeal membrane oxygenation with a review of the literature. Artif. Organs 2018, 42, 605-610. [CrossRef] [PubMed]

11. Gonçalves-Venade, G.; Lacerda-Príncipe, N.; Roncon-Albuquerque, R., Jr.; Paiva, J.A. Extracorporeal membrane oxygenation for refractory severe respiratory failure in acute interstitial pneumonia. Artif. Organs 2018, 42, 569-574. [CrossRef]

12. Sylvestre, A.; Adda, M.; Maltese, F.; Lannelongue, A.; Daviet, F.; Parzy, G.; Coiffard, B.; Roch, A.; Loundou, A.; Baumstarck, K.; et al. Long-term neurocognitive outcome is not worsened by of the use of veno venous ECMO in severe ARDS patients. Ann. Intensive Care 2019, 9, 1-10. [CrossRef] [PubMed]

13. Ramanathan, K.; Antognini, D.; Combes, A.; Paden, M.; Zakhary, B.; Ogino, M.; MacLaren, G.; Brodie, D.; Shekar, K. Planning and provision of ECMO services for severe ARDS during the COVID-19 pandemic and other outbreaks of emerging infectious diseases. Lancet Respir. Med. 2020, 8, 518-526. [CrossRef]

14. Luscher, T.F.; Creager, M.A.; Beckman, J.A.; Cosentino, F. Diabetes and vascular disease: Pathophysiology, clinical consequences, and medical therapy: Part II. Circulation 2003, 108, 1655-1661. [CrossRef] [PubMed]

15. Donath, M.Y.; Shoelson, S.E. Type 2 diabetes as an inflammatory disease. Nat. Rev. Immunol. 2011, 11, 98-107. [CrossRef] [PubMed]

16. Eguchi, K.; Manabe, I. Macrophages and islet inflammation in type 2 diabetes. Diabetes Obes. Metab. 2013, 5, 152-158. [CrossRef]

17. Xu, Y.; Xie, Y.; Shao, X.; Ni, Z.; Mou, S. L-FABP: A novel biomarker of kidney disease. Clin. Chim. Acta 2015, 445, 85-90. [CrossRef]

18. Hayashi, Y.; Sawa, Y.; Fukuyama, N.; Nakazawa, H.; Matsuda, H. Inducible nitric oxide production is an adaptation to cardiopulmonary bypass-induced inflammatory response. Ann. Thorac. Surg. 2001, 72, 149-155. [CrossRef]

19. Podgoreanu, M.V.; Michelotti, G.A.; Sato, Y.; Smith, M.P.; Lin, S.; Morris, R.W.; Grocott, H.P.; Mathew, J.P.; Schwinn, D.A. Differential cardiac gene expression during cardiopulmonary bypass: Ischemia-independent upregulation of proinflammatory genes. J. Thorac. Cardiovasc. Surg. 2005, 130, 330-339. [CrossRef]

20. Verrier, E.D.; Morgan, E.N. Endothelial response to car-Diopulmonary bypass surgery. Ann. Thorac. Surg. 1998, 66, 17-19. [CrossRef]

21. Alex, J.; Laden, G.; Cale, A.R.; Bennett, S.; Flowers, K.; Madden, L.; Gardiner, E.; McCollum, P.T.; Griffin, S.C. Pretreatment with hyperbaric oxygen and its effect on neuropsychometric dysfunction and systemic inflammatory response after cardiopulmonary bypass: A prospective randomized double-blind trial. J. Thorac. Cardiovasc. Surg. 2005, 130, 1623-1630. [CrossRef] [PubMed]

22. Mohammadi, S.; Dagenais, F.; Mathieu, P.; Kingma, J.G.; Doyle, D.; Lopez, S.; Baillot, R.; Perron, J.; Charbonneau, E.; Dumont, E.; et al. Long-term impact of diabetes and its comorbidities in patients undergoing isolated primary coronary artery bypass graft surgery. Circulation 2007, 116, I220-I225. [CrossRef]

23. Nishimoto, S.; Fukuda, D.; Higashikuni, Y.; Tanaka, K.; Hirata, Y.; Murata, C.; Kim-Kaneyama, J.R.; Sato, F.; Bando, M.; Yagi, S.; et al. Obesity-induced DNA released from adipocytes stimulates chronic adipose tissue inflammation and insulin resistance. Sci. Adv. 2016, 2, e150133. [CrossRef]

24. Tousoulis, D.; Kampoli, A.M.; Stefanadis, C. Diabetes mellit and vascular endothelial dysfunction: Current perspectives. Curr. Vasc. Pharmacol. 2012, 10, 19-32. [CrossRef]

25. Nosál'ová, V.; Drábiková, K.; Zúrová-Nedelcevová, J.; Jancinová, V.; Okruhlicová, L.; Nosál', R.; Sotníková, R. Ischaemia/reperfusioninduced organ injury in low dose streptozotocin diabetes. Neuro Endocrinol. Lett. 2006, 27, 152-155. [PubMed] 
26. Waskowski, J.; Pfortmueller, C.A.; Erdoes, G.; Buehlmann, R.; Messmer, A.S.; Luedi, M.M.; Schmidli, J.; Schefold, J.C. Mannitol for the prevention of peri-operative acute kidney injury: A systematic review. Eur. J. Vasc. Endovasc. Surg. 2019, 58, 130-140. [CrossRef]

27. Hu, J.; Chen, R.; Liu, S.; Yu, X.; Zou, J.; Ding, X. Global incidence and outcomes of adult patients with acute kidney injury after cardiac surgery: A systematic review and meta-analysis. J. Cardiothorac. Vasc. Anesth. 2016, 30, 82-89. [CrossRef] [PubMed]

28. Le Guillou, V.; Tamion, F.; Jouet, I.; Richard, V.; Mulder, P.; Bessou, J.P.; Doguet, F. Mesenteric endothelial dysfunction in a cardiopulmonary bypass rat model: The effect of diabetes. Diab. Vasc. Dis. Res. 2012, 9, 270-279. [CrossRef]

29. Funamoto, M.; Masumoto, H.; Takaori, K.; Taki, T.; Setozaki, S.; Yamazaki, K.; Minakata, K.; Ikeda, T.; Hyon, S.H.; Sakata, R. Green tea polyphenol prevents diabetic rats from acute kidney injury after cardiopulmonary bypass. Ann. Thorac. Surg. 2016, 101, 1507-1513. [CrossRef]

30. Marty, J.C.; Bendhadra, S.; Amoureux, S.; Guilland, J.C.; Vergely, C.; Rochette, L.; Girard, C. Oxidative stress is exacerbated in diabetic patients during cardiopulmonary bypass. Ann. Cardiol. Angeiol. (Paris) 2008, 57, 155-160. [CrossRef]

31. Xie, N.; Zhang, W.; Li, J.; Liang, H.; Zhou, H.; Duan, W.; Xu, X.; Yu, S.; Zhang, H.; Yi, D. $\alpha$-Linolenic acid intake attenuates myocardial ischemia/reperfusion injury through anti-inflammatory and anti-oxidative stress effects in diabetic but not normal rats. Arch. Med. Res. 2011, 42, 171-181. [CrossRef] [PubMed]

32. Mahmood, E.; Jeganathan, J.; Feng, R.; Saraf, M.; Khabbaz, K.; Mahmood, F.; Venkatachalam, S.; Liu, D.; Chu, L.; Parikh, S.M.; et al. Decreased PGC-1 $\alpha$ post-cardiopulmonary bypass leads to impaired oxidative stress in diabetic patients. Ann. Thorac. Surg. 2019, 107, 467-476. [CrossRef] [PubMed]

33. Cerrahoglu, M.; Taner, K.A.; Iskesen, I.; Onur, E.; Sirin, H. Calcium dobesilate reduces oxidative stress in cardiac surgery. J. Cardiovasc. Surg. (Torino) 2009, 50, 695-701.

34. Morita, K. Surgical reoxygenation injury of the myocardium in cyanotic patients: Clinical relevance and therapeutic strategies by normoxic management during cardiopulmonary bypass. Gen. Thorac. Cardiovasc. Surg. 2012, 60, 549-556. [CrossRef] [PubMed]

35. Goudeau, J.J.; Clermont, G.; Guillery, O.; Lemaire-Ewing, S.; Musat, A.; Vernet, M.; Vergely, C.; Guiguet, M.; Rochette, L.; Girard, C.; et al. In high-risk patients, combination of antiinflammatory procedures during cardiopulmonary bypass can reduce incidences of inflammation and oxidative stress. J. Cardiovasc. Pharmacol. 2007, 49, 39-45. [CrossRef]

36. Clermont, G.; Vergely, C.; Jazayeri, S.; Lahet, J.J.; Goudeau, J.J.; Lecour, S.; David, M.; Rochette, L.; Girard, C. Systemic free radical activation is a Major event involved in myocardial oxidative stress related to cardiopulmonary bypass. Anesthesiology 2002, 96, 80-87. [CrossRef] [PubMed]

37. Fujii, Y. The potential of the novel leukocyte removal filter in cardiopulmonary bypass. Expert Rev. Med. Devices 2016, 13, 5-14. [CrossRef]

38. Harm, S.; Schildböck, C.; Hartmann, J. Cytokine removal in extracorporeal blood purification: An in vitro study. Blood Purif. 2020, 49, 33-43. [CrossRef]

39. Moledina, D.G.; Parikh, C.R. Phenotyping of acute kidney injury: Beyond serumcreatinine. Semin. Nephrol. $2018,38,3-11$. [CrossRef] 